\title{
A New Paradigm Shift for the Green Synthesis of Antibacterial Silver Nanoparticles Utilizing Plant Extracts
}

\author{
Youmie Park \\ College of Pharmacy, Inje University, Gimhae, Korea
}

(Received September 3, 2014; Revised September 23, 2014; Accepted September 25, 2014)

\begin{abstract}
This review covers general information regarding the green synthesis of antibacterial silver nanoparticles. Owing to their antibacterial properties, silver nanoparticles are widely used in many areas, especially biomedical applications. In green synthesis practices, the chemical reducing agents are eliminated, and biological entities are utilized to convert silver ions to silver nanoparticles. Among the various biological entities, natural plant extracts have emerged as green reducing agents, providing eco-friendly routes for the preparation of silver nanomaterials. The most obvious merits of green synthesis are the increased biocompatibility of the resulting silver nanoparticles and the ease with which the reaction can be carried out. This review summarizes some of the plant extracts that are used to produce antibacterial silver nanoparticles. Additionally, background information regarding the green synthesis and antibacterial activity of silver nanoparticles is provided. Finally, the toxicological aspects of silver nanoparticles are briefly mentioned.
\end{abstract}

Key words: Plant extracts, Green synthesis, Silver nanoparticles, Antibacterial activity

\section{INTRODUCTION}

As an important aspect of nanotechnology, nanoparticles (NPs, less than $100 \mathrm{~nm}$ in one dimension) have been developed for a variety of applications, especially in the area of nanomedicine (1). NPs possess characteristic properties that differ from those of their bulk counterparts. In the area of nanomedicine, NPs are commonly employed as drug delivery vehicles. Recently, NPs have been employed in therapeutic applications to target specific sites, such as lung tissue, as well as in cancer therapy and vaccinations (1). Additionally, the use of NPs continues to increase in microbial applications due to the potential of NPs to circumvent microbial resistance while satisfying the current need for novel antibiotics (2-4). The number of infections and outbreaks associated with multi-drug-resistant (MDR) bacteria has increased, threatening public health. The NPs used to overcome microbial resistance include nitric oxide-releasing NPs, chitosan NPs and metallic NPs (3). Among the metallic NPs, the medicinal potentials of gold NPs (AuNPs)

\footnotetext{
Correspondence to: Youmie Park, College of Pharmacy, Inje University, 197 Inje-ro, Gimhae, Gyeongnam 621-749, Korea E-mail: youmiep@inje.ac.kr

This is an Open-Access article distributed under the terms of the Creative Commons Attribution Non-Commercial License (http:// creativecommons.org/licenses/by-nc/3.0) which permits unrestricted non-commercial use, distribution, and reproduction in any medium, provided the original work is properly cited.
}

and silver NPs (AgNPs) have been extensively discussed elsewhere (5). AgNPs possess excellent antibacterial, antiviral and antifungal activities (6). Metallic NPs are commonly synthesized by traditional chemical and physical methods (7). However, current sustainability issues have led to explorations of eco-friendly synthesis and green synthesis for the production of metallic NPs based on diverse biological entities (7). This review is not meant to be inclusive of all plant extracts utilized for the green synthesis of AgNPs. There are extensive reviews that address this area (8-12). Instead, this review focuses on the preparation of antibacterial AgNPs by using plant extracts as reducing agents.

\section{GREEN SYNTHESIS OF AgNPs}

Advantages and applications. The chemical synthesis of AgNPs employs chemical reducing agents to convert $\mathrm{Ag}$ ions to AgNPs. One of the most widely used chemical reducing agents is sodium borohydride. This process involves the undesired use of hazardous chemicals, and the biocompatibility of the resulting AgNPs is too low for application in biological systems. Relative to this traditional chemical method, methods of green synthesis that use environmentally friendly or eco-friendly compounds as reducing agents are emerging (13-19). The biological entities used for green synthesis include bacteria, fungi, plants, pure compounds from plants, algae, carbohydrates, microorganisms, etc. The 
process of green synthesis requires the use of water as an environmentally friendly solvent; of note is the fact that water is more biocompatible than organic solvents.

Green synthesis possesses the following advantages over traditional chemical methods. (1) green synthesis is simple and usually involves a one-pot reaction; (2) it is amenable to scale up; (3) the toxicity-associated hazardous chemicals are eliminated, increasing the biocompatibility of the resulting product with normal tissues for in vivo applications; and (4) green biological entities can be used as reducing agents and capping agents, providing AgNPs with enhanced colloidal stability. Colloidal stability is an important factor when making claims regarding the biological activity of AgNPs. (5) Finally, the process is cost-effective. These advantages are not limited to AgNPs. Other metallic NPs can be greensynthesized and have many uses in biomedical and industrial applications. There are extensive reviews elsewhere regarding the applications of green-synthesized metallic NPs $(20,21)$. The applications of metallic NPs include (1) biomedical applications, such as antimicrobial applications, drug delivery vehicles, medical imaging and diagnostics; (2) environmental remediation applications, such as the catalytic degradation of pollutants; and (3) industrial applications, such as energy-related applications and catalysis in organic synthesis (20). Borase et al. have extensively reviewed AgNPs in a variety of applications, including anticancer, catalysis, biosensor, drug delivery, textiles and cosmetics, antituberculosis, antiviral, insect management and water purification (12).

Procedures and characterization. We utilized various biological entities, including plant extracts (Leonurus japonicus, Artemisia capillaris, Polygala tenuifolia, and Caesalpinia sappan), a pure compound from plants (chlorogenic acid), polysaccharides (chondroitin sulfate and acharan sulfate), an oligosaccharide (sialyllactose) and invertebrate extracts (an African giant snail Achatina fulica and an earthworm Eisenia andrei), for the green synthesis of AgNPs (22-29). The green synthesis of AgNPs is a simple and facile approach that is carried out by mixing silver nitrate (the $\mathrm{Ag}$ ion source) with a biological entity (the reducing agent). A schematic representation of the synthesis process is depicted in Fig. 1. In our experiment, an external source of energy, for example, oven incubation, is used to facilitate the reaction. The applications that we evaluated were mainly antibacterial (minimum inhibitory concentration, MIC) and in vivo wound-healing activities. Remarkably, AgNPs synthesized with the extract of Leonurus japonicus exhibited enhanced antibacterial activities (approximately 127-fold increase) against Pseudomonas aeruginosa, Escherichia coli and Enterobacter cloacae (22). The aerial portion of Leonurus japonicus was utilized. In the case of AgNPs synthesized with the root extract of Polygala tenuifolia, the strain of Escherichia coli DC2 was shown to be the most effective when treated with AgNPs (approximately 16-fold increase) (24). The aerial portion of Artemisia capillaris was also used as a reducing agent for the synthesis of AgNPs and AgNPs enhance the antibacterial activity against Pseudomonas aeruginosa, Escherichia coli, Enterobacter cloacae, Klebsiella oxytoca and Klebsiella areogenes (23). In each case, MIC values are compared with values recorded for the original plant extract alone. Generally, AgNPs synthesized with the three plant extracts mentioned above show more effective antibacterial activities against Gram-negative than Gram-positive bacteria.

The formation of AgNPs is generally characterized with spectroscopic and microscopic methods, including UV-visible spectrophotometry, Fourier-transform infrared spectroscopy
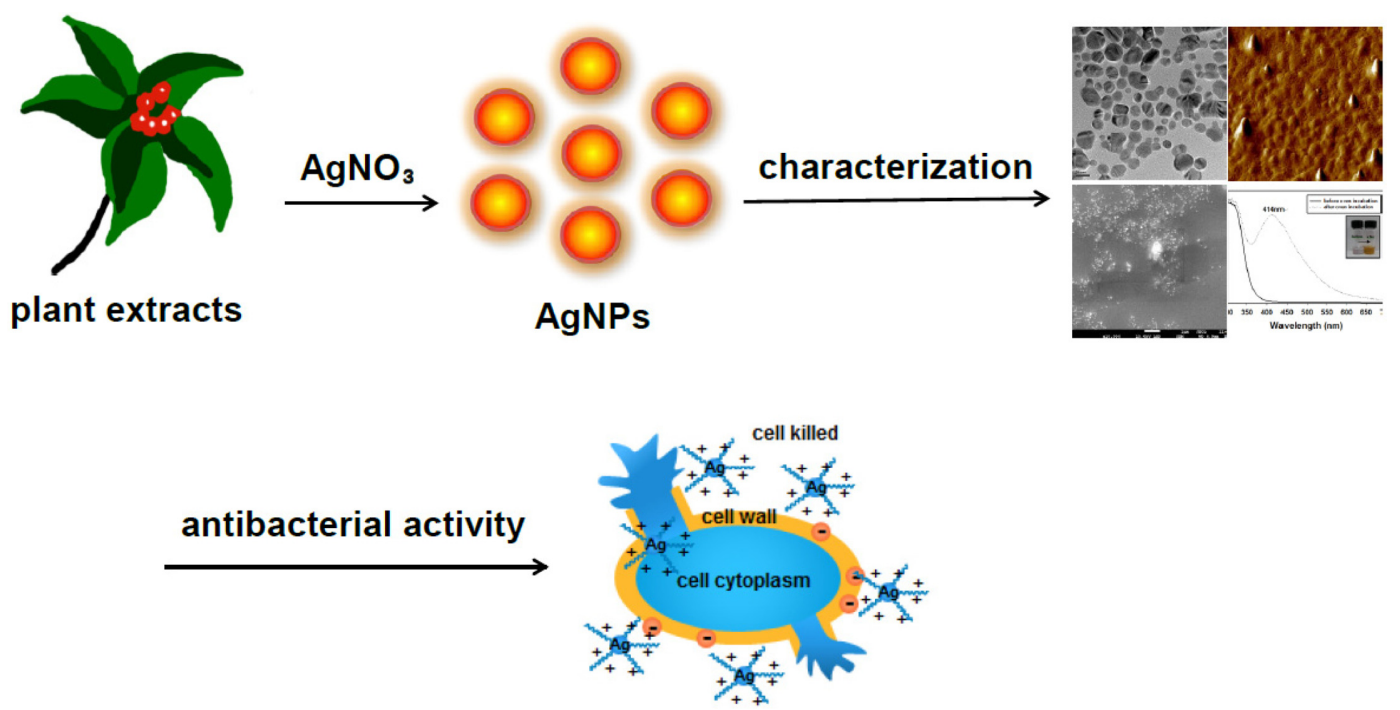

Fig. 1. A schematic of the procedure followed to synthesize AgNPs by using plant extracts as reducing agents. 
(FT-IR), scanning electron microscopy (SEM), transmission electron microscopy (TEM), atomic force microscopy (AFM), X-ray diffraction (XRD) and zeta potential measurements. The formation of AgNPs is initially judged based on the color change of the solution, using the naked eye. The characteristic absorbance is observed in the range of 380 450 nm (yellow color), in which predominantly spherical AgNPs are synthesized. When the synthesis is completed, the size, shape and dispersion state of AgNPs are commonly visualized and measured by microscopic methods, such as TEM, AFM and SEM. Next, the crystalline nature of AgNPs is confirmed by XRD analysis. FT-IR spectra provide information regarding the functional groups of the reducing agents that are involved in the reduction of $\mathrm{Ag}^{+}$to AgNPs. Further, zeta potential measurements give information regarding the surface charges of AgNPs, which affect their colloidal stability. The reaction yield is measured by using both ultracentrifugation and inductively coupled plasma mass spectrometry (ICP-MS). After performing ultracentrifugation, AgNPs settle to the bottom of the tube. The colorless supernatant solution containing the unreacted $\mathrm{Ag}^{+}$is pooled and analyzed by ICP-MS. Then, the yield can be calculated by measuring the concentrations of both the total $\mathrm{Ag}$ in the solution of AgNPs and the unreacted Ag in the supernatant.

\section{PLANT EXTRACTS AS REDUCING AGENTS FOR THE GREEN SYNTHESIS OF AgNPs}

Following various sustainability initiatives, plant extracts are emerging as potential reducing agents for the green syn- thesis of AgNPs. Various categories of plant extracts further act as stabilizing agents. Approximately 321,212 species of plants are known on earth, according to the Botanic Gardens Conservation International, indicating that researchers have access to a significant variety of natural plant material (12). The author extensively reviewed the green synthesis of AuNPs and AgNPs using polysaccharides and phytochemicals as reducing agents (13). Phytochemicals and plant-derived polysaccharides, such as cellulose, starch, dextran, and alginic acid, play dual roles as reducing and stabilizing agents. The oxidation of the hydroxyl groups of polysaccharides to carbonyl groups is most likely involved in the reduction of metal ions to produce metallic NPs (13).

Researchers have reported that four factors $-\mathrm{pH}$, temperature, reaction time and the ratio of plant extracts to silver nitrate-affect the synthesis of AgNPs based on plant extracts $(8,12)$. (1) By changing the $\mathrm{pH}$, the charges of the biomolecules in extracts are altered. Because the $\mathrm{Ag}$ ion is a cation, the charge of the biomolecules also affects the synthesis of AgNPs. (2) Generally, increasing the reaction temperature leads to a higher reaction rate. In high-temperature reactions, thermo-stable compounds can play a major role in obtaining higher yields. (3) Additionally, by increasing the reaction time, the reaction rate generally increases. (4) Finally, the ratio of plant extract to silver nitrate is a very important factor for obtaining AgNPs with various sizes and shapes.

The plant examples given in Table 1 are listed with their intrinsic biological activities and the plant parts used for synthesis. Leaves are the most commonly employed plant parts. Other parts used include bark, aerial part, fruit (whole or peeled), flower, root, tuber, rhizome, latex, moss, bulb,

Table 1. Plant extracts used for the green synthesis of antibacterial AgNPs

\begin{tabular}{|c|c|c|c|}
\hline \multicolumn{4}{|c|}{ Antibacterial AgNPs } \\
\hline Scientific name & Intrinsic biological activities of plants & $\begin{array}{l}\text { Plant part used } \\
\text { for the green } \\
\text { synthesis of AgNPs }\end{array}$ & Refs. \\
\hline \multirow{3}{*}{ Acalypha indica } & 1) analgesic and antiinflammatory activities & \multirow{3}{*}{ leaves } & \multirow{3}{*}{$(36)$} \\
\hline & 2) antituberculosis activity & & \\
\hline & 3) antibacterial activity & & \\
\hline Allium cepa & 1) antimicrobial activity & bulbs & $(37)$ \\
\hline \multirow{3}{*}{ Argemone maxicana } & 1) healing of gastric ulceration & \multirow[t]{3}{*}{ leaves } & \multirow[t]{3}{*}{$(38)$} \\
\hline & 2) larvicidal and chemosterilant activities & & \\
\hline & 1) antitumor activity & & \\
\hline \multirow[t]{5}{*}{ Artemisia capillaris } & 2) antiobesity activity & \multirow[t]{2}{*}{ aerial parts } & \multirow[t]{2}{*}{$(23)$} \\
\hline & 3) antiinflammatory activity & & \\
\hline & 1) antiproliferative activity & \multirow{8}{*}{ leaves } & \multirow{8}{*}{ (39) } \\
\hline & 2) antibacterial activity & & \\
\hline & 3) antimicrobial activity & & \\
\hline \multirow{5}{*}{ Artocarpus heterophyllus } & 4) inhibitory effect on human blood coagulation & & \\
\hline & 5) antioxidant activity & & \\
\hline & 6) hypoglycemic and hypolipidemic effects & & \\
\hline & 7) wound healing activity & & \\
\hline & 8) antiinflammatory activity & & \\
\hline
\end{tabular}


Table 1. Continued

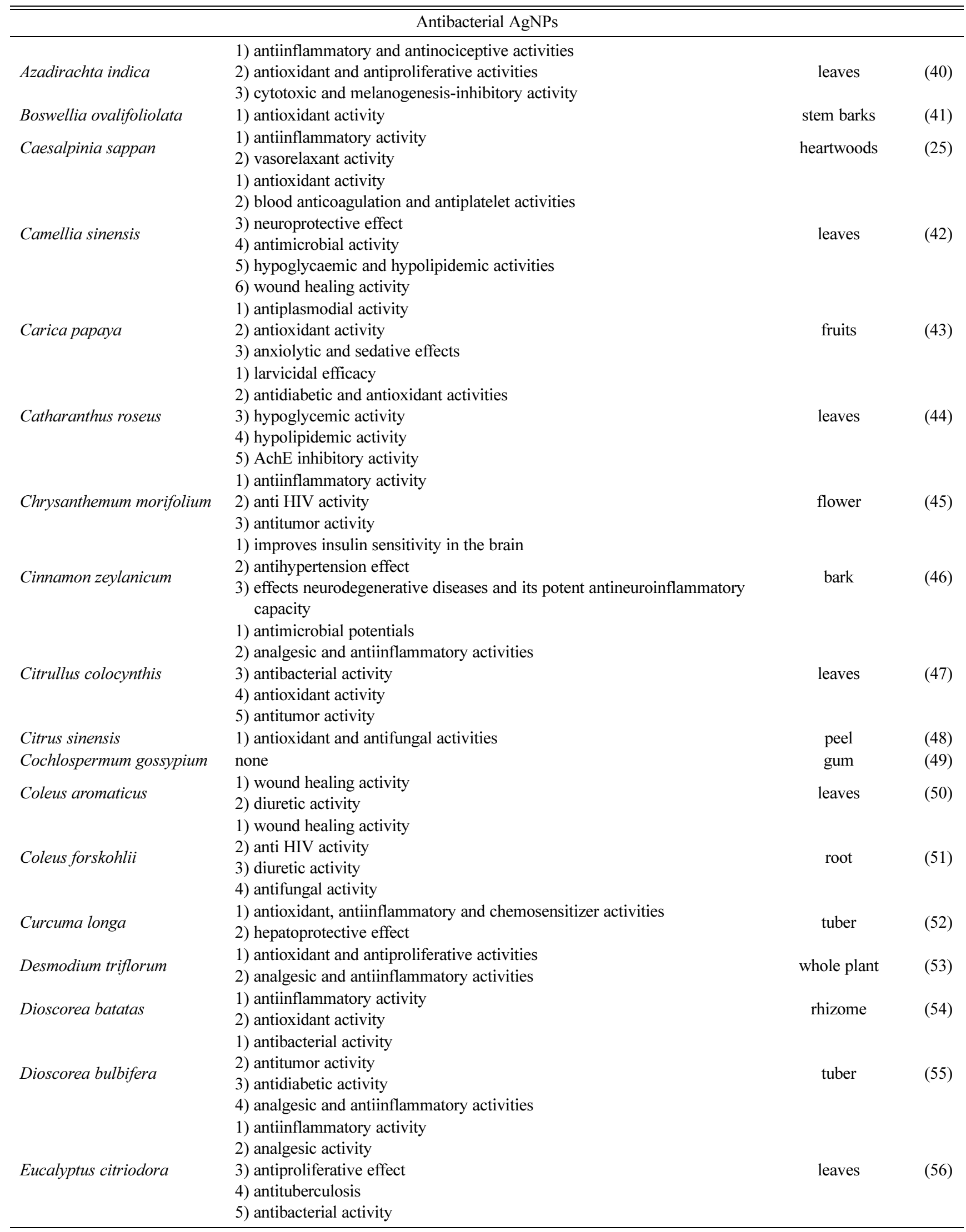


Table 1. Continued

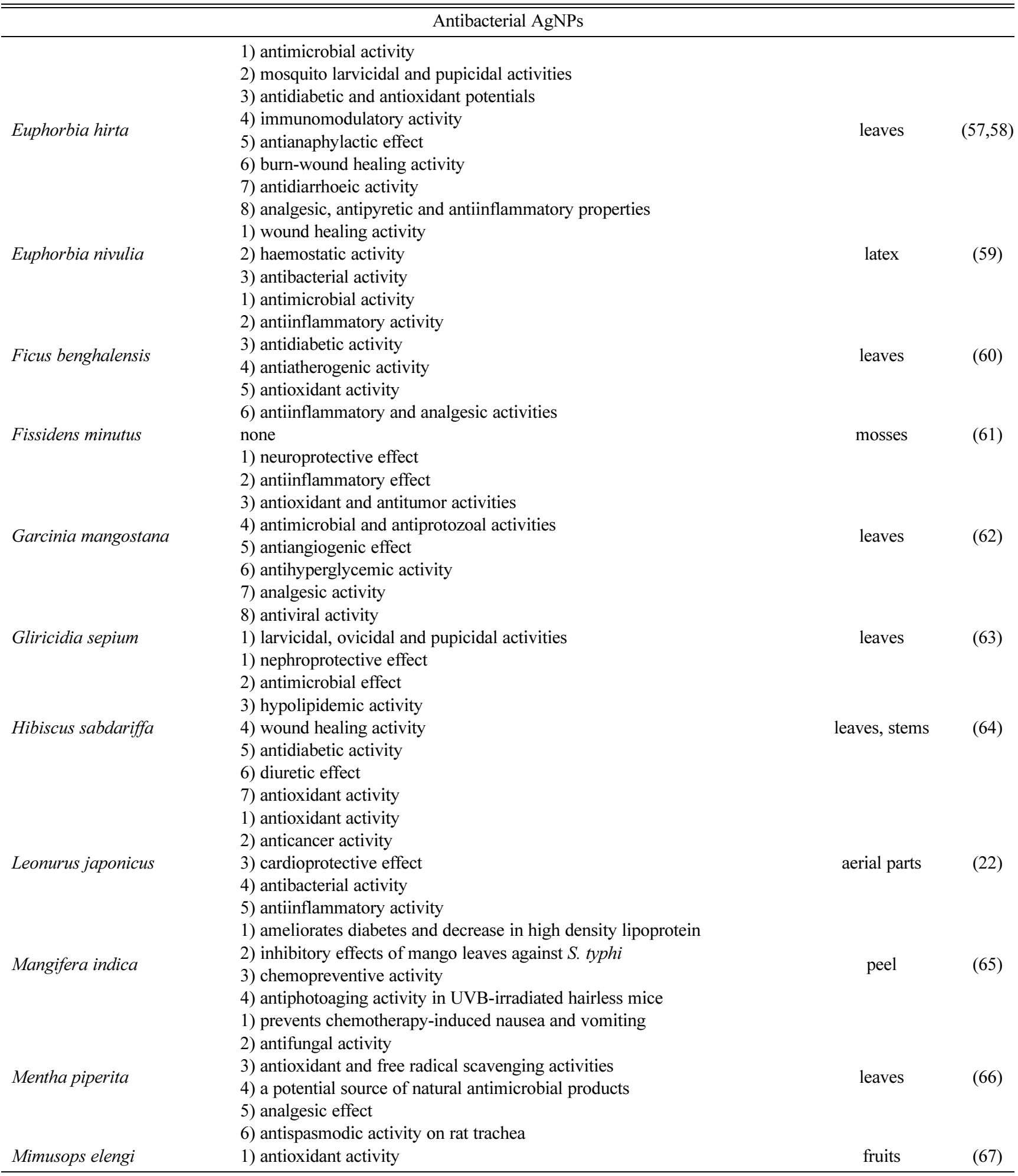

heartwood, gum, callus and seed. Borase et al. have listed the active components of plants that are responsible for reducing silver ions to AgNPs; according to these authors, the list of active components includes proteins, flavonoids, terpenoids, polyphenols, phenol hydroxyl and carboxylic groups of arabinose and galactose, phenolic glycosides, reducing sugars, tannins, aliphatic amines, aliphatic alkenes of alkaloids, polysaccharides, aromatic amines, sec-alcohols, 
Table 1. Continued

\begin{tabular}{|c|c|c|c|}
\hline \multicolumn{4}{|c|}{ Antibacterial AgNPs } \\
\hline Moringa oleifera & $\begin{array}{l}\text { 1) antimicrobial, anticancer, antiinflammatory, antidiabetic, and antioxidant } \\
\text { effects } \\
\text { 2) antidiabetic and antioxidant activities } \\
\text { 3) antiinflammatory activity } \\
\text { 4) hypoglycemia and hypolipidemia activities } \\
\text { 5) antioxidant capacity and antimicrobial activities } \\
\text { 6) antifungal activity } \\
\text { 7) recovery from hepatic damage } \\
\text { 8) antispasmodic, antiinflammatory and diuretic activities } \\
\text { 9) induces apoptosis }\end{array}$ & leaves & $(68)$ \\
\hline Musa paradisiaca & $\begin{array}{l}\text { 1) antioxidant, antimutagenic, anticarcinogenic, and cytoprotective activities } \\
\text { 1) antifungal activity }\end{array}$ & peel & $(69)$ \\
\hline Nerium indicum & $\begin{array}{l}\text { 2) antioxidant activity } \\
\text { 3) anticancer effects } \\
\text { 4) antidiabetic activity }\end{array}$ & leaves & $(58)$ \\
\hline Nicotiana tobaccum & none & leaves & $(70)$ \\
\hline Ocimum tenuiflorum & $\begin{array}{l}\text { 1) antihyperglycemic activity } \\
\text { 1) activity of the coagulants } \\
\text { 2) antibacterial activity } \\
\text { 3) inhibits the ulcerogenic activity }\end{array}$ & leaves & $(71)$ \\
\hline Opuntia ficus-indica & $\begin{array}{l}\text { 4) wound healing activity } \\
\text { 5) reduces hangover symptoms and inhibites the production of inflammatory } \\
\text { mediators } \\
\text { 6) hepatoprotective effect } \\
\text { 1) antiinflammatory activity }\end{array}$ & leaves & $(72)$ \\
\hline Polygala tenuifolia & $\begin{array}{l}\text { 2) antitumor activity } \\
\text { 3) anxiolytic activity }\end{array}$ & roots & $(24)$ \\
\hline Sesuvium portulacastrum & $\begin{array}{l}\text { 1) potential antimicrobial agent } \\
\text { 2) cholinesterase inhibitory activity }\end{array}$ & leaves, callus & (73) \\
\hline $\begin{array}{l}\text { Shorea tumbuggaia } \\
\text { Svensonia hyderabadensis }\end{array}$ & $\begin{array}{l}\text { 1) decreases cholesterol and triglycerides } \\
\text { none }\end{array}$ & $\begin{array}{l}\text { stem barks } \\
\text { leaves }\end{array}$ & $\begin{array}{l}(41) \\
(74)\end{array}$ \\
\hline Tribulus terrestris & $\begin{array}{l}\text { 1) antitumor and antiangiogenic activities } \\
\text { 2) large gains in strength and lean muscle mass } \\
\text { 3) inhibits oxidative stress } \\
\text { 4) reduces Cd load } \\
\text { 5) conventional analgesic drugs } \\
\text { 6) antihypertensive effect both systolic and diastolic } \\
\text { 7) antidepressive effect }\end{array}$ & fruits & $(75)$ \\
\hline Vitex negundo & $\begin{array}{l}\text { 1) treats various inflammatory disorders } \\
\text { 2) analgesic and antiinflammatory activities }\end{array}$ & leaves & $(76)$ \\
\hline
\end{tabular}

water-soluble heterocyclic components and saponins (12). Typically, plant extracts possess intrinsic biological activities, which may further manifest in the biological activities of AgNPs as a result of combining the two materials. Therefore, plant extracts can potentially be developed into novel nanomaterials with diverse biological activities.

\section{ANTIBACTERIAL ACTIVITIES OF AgNPs}

MDR bacteria. One of the most remarkable properties of AgNPs is their antibacterial activity. For 7,000 years, mankind has used Ag metal in coins, cutlery, textiles, cosmetics and medical implants. Ag has also been used as an antibacterial agent in the form of ions, NPs and bulk metal (30). Currently, the increased use of AgNPs in medicine is closely associated with the antibacterial potential of AgNPs. The emergence of MDR bacteria requires novel antibiotics with improved antibacterial activities. In most respects, AgNPs have appeared as prospective alternatives for overcoming antibiotic resistance problems because AgNPs utilize multivalent or polyvalent mechanisms to exert their antibacterial activities. Additionally, the high surface-areato-volume ratio and the specific physical and chemical characteristics of AgNPs make them effective antibacterial agents against MDR bacteria, which includes methicillinresistant Staphylococcus aureus (MRSA), methicillin-sensitive 
Staphylococcus aureus (MSSA), methicillin-resistant Staphylococcus epidermis (MRSE), ampicillin-resistant Escherichia coli, vancomycin-resistant Staphylococcus aureus (VRSA), erythromycin-resistant Streptococcus pyogenes and multidrug-resistant Pseudomonas aeruginosa (31).

Mechanisms. The antibacterial mechanisms of AgNPs are not yet fully understood; however, the research community has put forward several hypotheses, which follow (31). (1) AgNPs penetrate the cell wall of Gram-negative bacteria, leading to increased cell permeability followed by cell death; (2) the formation of free radicals by AgNPs is attributed to membrane damage; and (3) the strong binding capacity of $\mathrm{Ag}^{+}$with thiol groups and phosphorous-containing bases, such as vital enzymes and DNA bases, causes the inhibition of bacterial growth and death. Key factors, such as size and shape, affect the antibacterial activity of AgNPs (31). With decreasing size, the surface-area-to-volume ratio increases. The large surface area provides many opportunities for interactions with bacteria; thus, the small particle size is effective as an antibacterial agent. Pal et al. reported that triangular AgNPs are more active than spherical and rod-shaped AgNPs against Escherichia coli, suggesting that the shape of AgNPs should be considered to develop highly efficient antibacterial agents (32).

Stabilizers. For antibacterial applications of AgNPs, the colloidal stability is a major consideration. Thus, stabilizers are commonly employed to increase the stability of AgNPs. The most widely used stabilizers are anionic, cationic, and nonionic surfactants and polymers. Carmona-Ribeiro and de Melo Carrasco have reported that cationic compounds, especially compounds with quaternary ammonium groups, are promising candidates for the development of antimicrobial agents (33). One cationic surfactant, cetyltrimethylammonium bromide (CTAB), has been employed as a stabilizing agent during the synthesis of AgNPs. The mechanism of CTAB adsorption onto the AgNPs is not clearly understood; however, the formation of a CTAB bilayer is a possibility (34). As shown in Fig. 2A, the cationic head group of CTAB binds to the surface of AgNPs, with the hydrophilic group of the surfactant attaching to the AgNPs. Then, the outward hydrophobic tail binds to the hydrophobic tail of another CTAB molecule to form a bilayer structure. Consequently, due to the bilayer formation, the hydrophilic head group of CTAB is directed outward, contributing to the overall positive charge of CTAB-stabilized AgNPs (Fig. 2B). We performed a green synthesis reaction for AgNPs by using extract of Caesalpinia sappan in both the absence and presence of stabilizers. The stabilizers used were a nonionic polymer (PVP) and cationic (CTAB), anionic (SDS, NaDDSS) and nonionic (Tween 20 and 80) surfactants (25). Among the tested stabilizers, CTAB-stabilized AgNPs were found to be the most potent antibacterial agents against 19
(A)

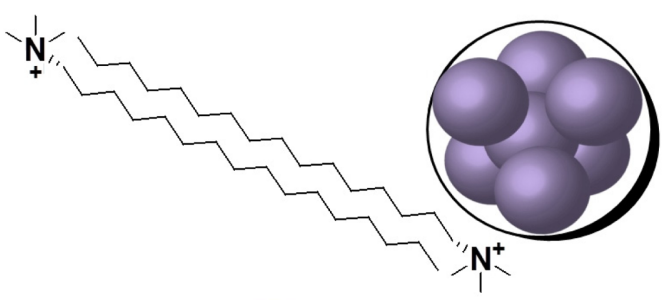

(B)
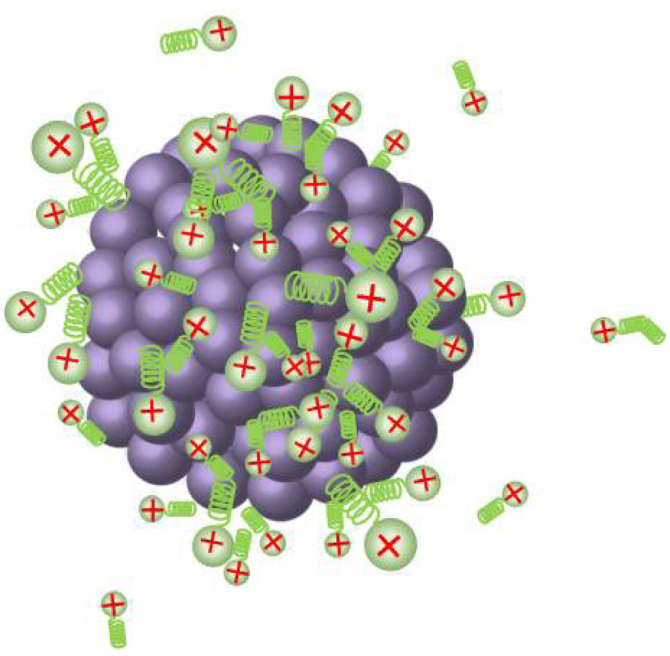

Fig. 2. The binding of $C T A B$ on the AgNP surface. (A) The bilayer formation of CTAB, and (B) CTAB-stabilized AgNPs with overall positive charges (34).

strains of MRSA (25). The bilayer shell of CTAB provides improved colloidal stability to the AgNPs, which is closely connected to their enhanced antibacterial activity against MRSA. The overall positive charge of the CTAB-stabilized AgNPs offers many opportunities for the NPs to interact with the negatively charged bacterial cell wall.

\section{PERSPECTIVES}

Currently, AgNPs-based consumer products are widespread in medical devices, clothing, industry, household goods, healthcare products and cosmetics (35). The potent antimicrobial activity of AgNPs is a key feature being utilized in the development of nanosilver products. Additionally, as a result of the increasing interest in the use of AgNPs in medical applications, the number of scientific publications on this subject has risen 41-fold since the last decade (2000 2011) (35). Whereas there were only four related publications in 2000, the number of publication increased to 164 in 2011 when a PubMed database search was performed using the keyword 'nanosilver' (35). In spite of the broad range of AgNP therapeutic applications, the limited information has been reported regarding the toxicity of AgNPs. One mechanism of AgNPs-induced toxicity is cellular apoptosis, which decreases cell viability (6). Safety issues concerning the environment should also be considered because AgNPs 
from consumer products enter ecosystems. However, understanding the toxicity and fate of AgNPs in ecosytems requires further investigation (6). The green synthetic strategy of AgNPs based on plant extracts, as reported in the current review, contributes to the protection of the ecosystem and our health by decreasing the use of toxicity-associated hazardous chemicals. Again, due to the increasing number of applications of AgNPs, the associated toxicity and safety issues should be investigated in depth to further the safe use of AgNPs.

\section{ACKNOWLEDGEMENTS}

This work was supported by a National Research Foundation of Korea (NRF) grant funded by the Korean government through the Ministry of Education (NRF-2012R1A1A2042224). The author thanks Ms. Sang Hui Jun and Ms. Hye Sung Lee for their assistance with manuscript preparation.

\section{REFERENCES}

1. Thorley, A.J. and Tetley, T.D. (2013) New perspectives in nanomedicine. Pharmacol. Ther, 140, 176-185.

2. Aruguete, D.M., Kim, B., Hochella, M.F. Jr., Ma, Y., Cheng, Y., Hoegh, A., Liu, J. and Pruden, A. (2013) Antimicrobial nanotechnology: its potential for the effective management of microbial drug resistance and implications for research needs in microbial nanotoxicology. Environ. Sci. Processes Impacts, 15, 93-102.

3. Pelgrift, R.Y. and Friedman, A.J. (2013) Nanotechnology as a therapeutic tool to combat microbial resistance. Adv. Drug Delivery Rev., 65, 1803-1815.

4. Seil, J.T. and Webster, T.J. (2012) Antimicrobial applications of nanotechnology: methods and literature. Int. J. Nanomed., 7, 2767-2781.

5. Loomba, L. and Scarabelli, T. (2013) Metallic nanoparticles and their medicinal potential. Part I: gold and silver colloids. Ther. Delivery, 4, 859-873.

6. dos Santos, C.A., Seckler, M.M., Ingle, A.P., Gupta, I., Galdiero, S., Galdiero, M., Gade, A. and Rai, M. (2014) Silver nanoparticles: therapeutical uses, toxicity, and safety issues. J. Pharm. Sci., 103, 1931-1944.

7. Nath, D. and Banerjee, P. (2013) Green nanotechnology - a new hope for medical biology. Environ. Toxicol. Pharmacol., 36, 997-1014.

8. Akhtar, M.S., Panwar, J. and Yun, Y.S. (2013) Biogenic synthesis of metallic nanoparticles by plant extracts. ACS Sustainable Chem. Eng., 1, 591-602.

9. Baker, S., Rakshith, D., Kavitha, K.S., Santosh, P., Kavitha, H.U., Rao, Y. and Satish, S. (2013) Plants: emerging as nanofactories towards facile route in synthesis of nanoparticles. Bioimpacts, 3, 111-117.

10. Rai, M. and Yadav, A. (2013) Plants as potential synthesiser of precious metal nanoparticles: progress and prospects. IET Nanobiotechnol., 7, 117-124.

11. Mittal, A.K., Chisti, Y. and Banerjee, U.C. (2013) Synthesis of metallic nanoparticles using plant extracts. Biotechnol. Adv.,
31, 346-356.

12. Borase, H.P., Salunke, B.K., Salunkhe, R.B., Patil, C.D., Hallsworth, J.E., Kim, B.S. and Patil, S.V. (2014) Plant extract: a promising biomatrix for ecofriendly, controlled synthesis of silver nanoparticles. Appl. Biochem. Biotechnol., 173, 1-29.

13. Park, Y., Hong, Y.N., Weyers, A., Kim, Y.S. and Linhardt, R.J. (2011) Polysaccharides and phytochemicals: a natural reservoir for the green synthesis of gold and silver nanoparticles. IET Nanobiotechnol., 5, 69-78.

14. Roy, N., Gaur, A., Jain, A., Bhattacharya, S. and Rani, V. (2013) Green synthesis of silver nanoparticles: an approach to overcome toxicity. Environ. Toxicol. Pharmacol., 36, 807-812.

15. Quester, K., Avalos-Borja, M. and Castro-Longoria, E. (2013) Biosynthesis and microscopic study of metallic nanoparticles. Micron, 54-55, 1-27.

16. Kharissova, O.V., Dias, H.V., Kharisov, B.I., Pérez, B.O. and Pérez, V.M. (2013) The greener synthesis of nanoparticles. Trends Biotechnol., 31, 240-248.

17. Poulose, S., Panda, T., Nair, P.P. and Theodore, T. (2014) Biosynthesis of silver nanoparticles. J. Nanosci. Nanotechnol., 14, 2038-2049.

18. Sharma, V.K., Yngard, R.A. and Lin, Y. (2009) Silver nanoparticles: green synthesis and their antimicrobial activities. Adv. Colloid Interface Sci., 145, 83-96.

19. Ghaseminezhad, S.M., Hamedi, S. and Shojaosadati, S.A. (2012) Green synthesis of silver nanoparticles by a novel method: comparative study of their properties. Carbohydr. Polym., 89, 467-472.

20. Schröfel, A., Kratošová, G., Safařík, I., Safaříková, M., Raška, I. and Shor, L.M. (2014) Applications of biosynthesized metallic nanoparticles - A review. Acta Biomater., 10, 4023-4042.

21. Majdalawieh, A., Kanan, M.C., El-Kadri, O. and Kanan, S.M. (2014) Recent advances in gold and silver nanoparticles: synthesis and applications. J. Nanosci. Nanotechnol., 14, 47574780 .

22. Im, A.R., Han, L., Kim, E.R., Kim, J., Kim, Y.S. and Park, Y. (2012) Enhanced antibacterial activities of leonuri herba extracts containing silver nanoparticles. Phytother. Res., 26, 1249-1255.

23. Park, Y., Noh, H.J., Han, L., Kim, H.S., Kim, Y.J., Choi, J.S., Kim, C.K., Kim, Y.S. and Cho, S. (2012) Artemisia capillaris extracts as a green factory for the synthesis of silver nanoparticles with antibacterial activities. J. Nanosci. Nanotechnol., 12, 7087-7095.

24. Jun, S.H., Cha, S.H., Kim, J., Cho, S. and Park, Y. (2015) Crystalline silver nanoparticles by using Polygala tenuifolia root extract as a green reducing agents. J. Nanosci. Nanotechnol., in press.

25. Jun, S.H., Cha, S.H., Kim, J.H., Yoon, M., Cho, S. and Park, Y. (2015) Silver nanoparticles synthesized using Caesalpinia sappan extract as potential novel nanoantibiotics against methicillin-resistant Staphylococcus aureus. J. Nanosci. Nanotechnol., in press.

26. Noh, H.J., Kim, H.S., Jun, S.H., Kang, Y.H., Cho, S. and Park, Y. (2013) Biogenic silver nanoparticles with chlorogenic acid as a bioreducing agent. J. Nanosci. Nanotechnol., 13, 57875793. 
27. Im, A.R., Kim, J.Y., Kim, H.S., Cho, S., Park, Y. and Kim, Y.S. (2013) Wound healing and antibacterial activities of chondroitin sulfate- and acharan sulfate-reduced silver nanoparticles. Nanotechnology, 24, 395102.

28. Noh, H.J., Im, A.R., Kim, H.S., Sohng, J.K., Kim, C.K., Kim, Y.S., Cho, S. and Park, Y. (2012) Antibacterial activity and increased freeze-drying stability of sialyllactose-reduced silver nanoparticles using sucrose and trehalose. J. Nanosci. Nanotechnol., 12, 3884-3895.

29. Han, L., Kim, Y.S., Cho, S. and Park, Y. (2013) Invertebrate water extracts as biocompatible reducing agents for the green synthesis of gold and silver nanoparticles. Nat. Prod. Commun., 8, 1149-1152.

30. Chernousova, S. and Epple, M. (2013) Silver as antibacterial agent: ion, nanoparticle, and metal. Angew. Chem. Int. Ed. Engl., 52, 1636-1653.

31. Rai, M.K., Deshmukh, S.D., Ingle, A.P. and Gade, A.K. (2012) Silver nanoparticles: the powerful nanoweapon against multidrug-resistant bacteria. J. Appl. Microbiol., 112, 841-852.

32. Pal, S., Tak, Y.K. and Song, J.M. (2007) Does the antibacterial activity of silver nanoparticles depend on the shape of the nanoparticle? A study of the Gram-negative bacterium Escherichia coli. Appl. Environ. Microbiol., 73, 1712-1720.

33. Carmona-Ribeiro, A.M. and de Melo Carrasco, L.D. (2013) Cationic antimicrobial polymers and their assemblies. Int. J. Mol. Sci., 14, 9906-9946.

34. Sui, Z.M., Chen, X., Wang, L.Y., Xu, L.M., Zhuang, W.C., Chai, Y.C. and Yang, C.J. (2006) Capping effect of CTAB on positively charged Ag nanoparticles. Phys. E (Amsterdam Neth.), 33, 308-314.

35. Schluesener, J.K. and Schluesener, H.J. (2013) Nanosilver: application and novel aspects of toxicology. Arch. Toxicol., 87, 569-576.

36. Krishnaraj, C., Jagan, E.G., Rajasekar, S., Selvakumar, P., Kalaichelvan, P.T. and Mohan, N. (2010) Synthesis of silver nanoparticles using Acalypha indica leaf extracts and its antibacterial activity against water borne pathogens. Colloids Surf. B Biointerfaces, 76, 50-56.

37. Saxena, A., Tripathi, R.M. and Singh, R.P. (2010) Biological synthesis of silver nanoparticles by using onion (Allium cepa) extract and their antibacterial activity. Dig. J. Nanomater. Biostruct., 5, 427-432.

38. Singh, A., Jain, D., Upadhyay, M.K., Khandelwal, N. and Verma, H.N. (2010) Green synthesis of silver nanoparticles using Agremone mexicana leaf extract and evaluation of their antimicrobial activities. Dig. J. Nanomater. Biostruct., 5, 483489 .

39. Thirumurugan, A., Tomy, N.A., Jai ganesh, R. and Gobikrishnan, S. (2010) Biological reduction of silver nanoparticles using plant leaf extracts and its effect on increased antimicrobial activity against clinically isolated organism. Der Pharma Chemica, 2, 279-284.

40. Tripathi, A., Chandrasekaran, N., Raichur, A.M. and Mukherjee, A. (2009) Antibacterial applications of silver nanoparticles synthesized by aqueous extract of Azadirachta indica (Neem) leaves. J. Biomed. Nanotechnol., 5, 93-98.

41. Savithramma, N., Linga Rao, M. and Suvarnalatha Devi, P. (2011) Evaluation of antibacterial efficacy of biologically synthesized silver nanoparticles using stem barks of Boswellia ovalifoliolata Bal. and Henry and Shorea tumbuggaia Roxb. J. Biol. Sci., 11, 39-45.

42. Vaseeharan, B., Ramasamy, P. and Chen, J.C. (2010) Antibacterial activity of silver nanoparticles (AgNps) synthesized by tea leaf extracts against pathogenic Vibrio harveyi and its protective efficacy on juvenile Feneropenaeus indicus. Lett. Appl. Microbiol., 50, 352-356.

43. Jain, D., Daima, H.K., Kachhwaha, S. and Kothari, S.L. (2009) Synthesis of plant-mediated silver nanoparticles using papaya fruit extract and evaluation of their antimicrobial activities. Dig. J. Nanomater. Biostruct., 4, 723-727.

44. Mukunthan, K.S., Elumalai, E.K., Patel, T.N. and Murty, V.R. (2011) Catharanthus roseus: a natural source for the synthesis of silver nanoparticles. Asian Pac. J. Trop. Biomed., 1, 270274.

45. He, Y., Du, Z., Lv, H., Jia, Q., Tang, Z., Zheng, X., Zhang, K. and Zhao, F. (2013) Green synthesis of silver nanoparticles by Chrysanthemum morifolium Ramat. extract and their application in clinical ultrasound gel. Int. J. Nanomed., 8, 1809-1815.

46. Sathishkumar, M., Sneha, K., Won, S.W., Cho, C.W., Kim, S. and Yun, Y.S. (2009) Cinnamon zeylanicum bark extract and powder mediated green synthesis of nano-crystalline silver particles and its bactericidal activity. Colloids Surf. B Biointerfaces, 73, 332-338.

47. Satyavani, K., Ramanathan, T. and Gurudeeban, S. (2011) Green synthesis of silver nanoparticles by using stem derived callus extract of bitter apple (Citrullus colocynthis). Dig. J. Nanomater. Biostruct., 6, 1019-1024.

48. Kaviya, S., Santhanalakshmi, J., Viswanathan, B., Muthumary, J. and Srinivasan, K. (2011) Biosynthesis of silver nanoparticles using Citrus sinensis peel extract and its antibacterial activity. Spectrochim. Acta A Mol. Biomol. Spectrosc., 79, 594-598.

49. Kora, A.J., Sashidhar, R.B. and Arunachalam, J. (2010) Gum kondagogu (Cochlospermum gossypium): A template for the green synthesis and stabilization of silver nanoparticles with antibacterial application. Carbohydr. Polym., 82, 670-679.

50. Vanaja, M. and Annadurai, G. (2013) Coleus aromaticus leaf extract mediated synthesis of silver nanoparticles and its bactericidal activity. Appl. Nanosci., 3, 217-223.

51. Naraginti, S. and Sivakumar, A. (2014) Eco-friendly synthesis of silver and gold nanoparticles with enhanced bactericidal activity and study of silver catalyzed reduction of 4nitrophenol. Spectrochim. Acta A Mol. Biomol. Spectrosc., 128, 357-362.

52. Sathishkumar, M., Sneha, K. and Yun, Y.S. (2010) Immobilization of silver nanoparticles synthesized using Curcuma longa tuber powder and extract on cotton cloth for bactericidal activity. Bioresour. Technol., 101, 7958-7965.

53. Ahmad, N., Sharma, S., Singh, V.N., Shamsi, S.F., Fatma, A. and Mehta, B.R. (2011) Biosynthesis of silver nanoparticles from Desmodium triflorum: A novel approach towards weed utilization. Biotechnol. Res. Int., 2011, 454090.

54. Nagajyothi, P.C. and Lee, K.D. (2011) Synthesis of plantmediated silver nanoparticles using Dioscorea batatas rhizome extract and evaluation of their antimicrobial activities. $J$. Nanomater., 2011, 573429.

55. Ghosh, S., Patil, S., Ahire, M., Kitture, R., Kale, S., Pardesi, K., Cameotra, S.S., Bellare, J., Dhavale, D.D., Jabgunde, A. 
and Chopade, B.A. (2012) Synthesis of silver nanoparticles using Dioscorea bulbifera tuber extract and evaluation of its synergistic potential in combination with antimicrobial agents. Int. J. Nanomed., 7, 483-496.

56. Ravindra, S., Murali Mohan, Y., Narayana Reddy, N. and Mohana Raju, K. (2010) Fabrication of antibacterial cotton fibres loaded with silver nanoparticles via "green approach". Colloids Surf. A, 367, 31-40.

57. Elumalai, E.K., Prasad, T.N.V.K.V., Hemachandran, J., Viviyan Therasa, S., Thirumalai, T. and David, E. (2010) Extracellular synthesis of silver nanoparticles using leaves of Euphorbia hirta and their antibacterial activities. J. Pharm. Sci. Res., 2, 549-554.

58. Mano Priya, M., Karunai Selvi, B. and John Paul, J.A. (2011) Green synthesis of silver nanoparticles from the leaf extracts of Euphorbia hirta and Nerium indicum. Dig. J. Nanomater. Biostruct., 6, 869-877.

59. Valodkar, M., Nagar, P.S., Jadeja, R.N., Thounaojam, M.C., Devkar, R.V. and Thakore, S. (2011) Euphorbiaceae latex induced green synthesis of non-cytotoxic metallic nanoparticle solutions: A rational approach to antimicrobial applications. Colloids Surf. A, 384, 337-344.

60. Saxena, A., Tripathi, R.M., Zafar, F. and Singh, P. (2012) Green synthesis of silver nanoparticles using aqueous solution of Ficus benghalensis leaf extract and characterization of their antibacterial activity. Mater. Lett., 67, 91-94.

61. Srivastava, A.A., Kulkarni, A.P., Harpale, P.M. and Zunjarrao, R.S. (2011) Plant mediated synthesis of silver nanoparticles using a bryophyte: Fissidens minutus and its antimicrobial activity. Int. J. Eng. Sci. Technol., 3, 8342-8347.

62. Veerasamy, R., Xin, T.Z., Gunasagaran, S., Xiang, T.F.W., Yang, E.F.C., Jeyakumar, N. and Dhanaraj, S.A. (2011) Biosynthesis of silver nanoparticles using mangosteen leaf extract and evaluation of their antimicrobial activities. J. Saudi Chem. Soc., 15, 113-120.

63. Rajesh, R.W., Jaya, L.R., Niranjan, K.S., Vijay, M.D. and Sahebrao, K.B. (2009) Phytosynthesis of silver nanoparticle using Gliricidia sepium (Jacq.). Curr. Nanosci., 5, 117-122.

64. Vinod Kumar, V., Anbarasan, S., Christena, L.R., SaiSubramanian, N. and Philip Anthony, S. (2014) Bio-functionalized silver nanoparticles for selective colorimetric sensing of toxic metal ions and antimicrobial studies. Spectrochim. Acta A Mol. Biomol. Spectrosc., 129, 35-42.

65. Yang, N. and Li, W.H. (2013) Mango peel extract mediated novel route for synthesis of silver nanoparticles and antibacterial application of silver nanoparticles loaded onto non-woven fabrics. Ind. Crops Prod., 48, 81-88.
66. MubarakAli, D., Thajuddin, N., Jeganathan, K. and Gunasekaran, M. (2011) Plant extract mediated synthesis of silver and gold nanoparticles and its antibacterial activity against clinically isolated pathogens. Colloids Surf. B Biointerfaces, 85, 360-365.

67. Kiran Kumar, H.A., Mandal, B.K., Mohan Kumar, K., Maddinedi, S., Sai Kumar, T., Madhiyazhagan, P. and Ghosh, A.R. (2014) Antimicrobial and antioxidant activities of Mimusops elengi seed extract mediated isotropic silver nanoparticles. Spectrochim. Acta A Mol. Biomol. Spectrosc., 130, 13-18.

68. Prasad, T.N. and Elumalai, E.K. (2011) Biofabrication of Ag nanoparticles using Moringa oleifera leaf extract and their antimicrobial activity. Asian Pac. J. Trop. Biomed., 1, 439442.

69. Bankar, A., Joshi, B., Kumar, A.R. and Zinjarde, S. (2010) Banana peel extract mediated novel route for the synthesis of silver nanoparticles. Colloids Surf. A, 368, 58-63.

70. Prasad, K.S., Pathak, D., Patel, A., Dalwadi, P., Prasad, R., Patel, P. and Selvaraj, K. (2011) Biogenic synthesis of silver nanoparticles using Nicotiana tobaccum leaf extract and study of their antibacterial effect. Afr. J. Biotechnol., 10, 8122-8130.

71. Patil, R.S., Kokate, M.R. and Kolekar, S.S. (2012) Bioinspired synthesis of highly stabilized silver nanoparticles using Ocimum tenuiflorum leaf extract and their antibacterial activity. Spectrochim. Acta A Mol. Biomol. Spectrosc., 91, 234-238.

72. Gade, A., Gaikwad, S., Tiwari, V., Yadav, A., Ingle, A. and Rai, M. (2010) Biofabrication of silver nanoparticles by Opuntia ficus-indica: In vitro antibacterial activity and study of the mechanism involved in the synthesis. Curr. Nanosci., 6, 370-375.

73. Nabikhan, A., Kandasamy, K., Raj, A. and Alikunhi, N.M. (2010) Synthesis of antimicrobial silver nanoparticles by callus and leaf extracts from saltmarsh plant, Sesuvium portulacastrum L. Colloids Surf. B Biointerfaces, 79, 488-493.

74. Linga Rao, M. and Savithramma, N. (2011) Biological synthesis of silver nanoparticles using Svensonia Hyderabadensis leaf extract and evaluation of their antimicrobial efficacy. $J$. Pharm. Sci. Res., 3, 1117-1121.

75. Gopinath, V., MubarakAli, D., Priyadarshini, S., Priyadharsshini, N.M., Thajuddin, N. and Velusamy, P. (2012) Biosynthesis of silver nanoparticles from Tribulus terrestris and its antimicrobial activity: a novel biological approach. Colloids Surf. B Biointerfaces, 96, 69-74.

76. Zargar, M., Hamid, A.A., Bakar, F.A., Shamsudin, M.N., Shameli, K., Jahanshiri, F. and Farahani, F. (2011) Green synthesis and antibacterial effect of silver nanoparticles using Vitex negundo L. Molecules, 16, 6667-6676. 